\title{
Analisa Unjuk Kerja Sistem PLTG di PT Indonesia Power Unit Pembangkitan Bali
}

\author{
Musa Aleksander Partogi ${ }^{1)^{*}}$, ( G B Wijaya Kusuma ${ }^{1)}$, K Astawa ${ }^{1)}$ \\ 1) Jurusan Teknik Mesin, Fakultas Teknik, Universitas Udayana \\ Kampus Bukit Jimbaran, Bali 80362 \\ Email: widigdha@yahoo.com
}

doi: https://doi.org/10.24843/METTEK.2018.v04.101.p03

\begin{abstract}
Abstrak
Pembangkit Listrik Tenaga Gas (PLTG) merupakan salah satu mesin pembangkit yang digunakan PT. Indonesia Power UP Bali dalam kegiatan industri pembangkit di Indonesia. Dalam pengoperasiannya mulai tahun 1994 hingga sekarang mesin PLTG masih menggunakan minyak solar/HSD sebagai bahan bakar pembangkit. Penelitian ini dimaksudkan untuk menganalisa unjuk kerja sistem PLTG khususnya analisa keekonomian dengan membandingkan penggunaan bahan bakar minyak solar dan gas pada mesin pembangkit. Spesific Fuel Consumption (SFC) adalah rasio perbandingan total konsumsi bahan bakar terhadap daya listrik yang dibangkitkan, SFC digunakan sebagai salah satu cara untuk mengetahui seberapa efisien sebuah mesin pembangkit dan salah satu penentu biaya produksi khususnya biaya bahan bakar yang diperlukan dalam pembangkit. Berdasarkan hasil penelitian dengan harga minyak solar/HSD Rp 7300,- /liter dan gas US \$11/mmBTU, didapatkan biaya produksi listrik bahan bakar HSD secara aktual sebesar Rp 2541,86/kWh, secara teoritis Rp 2336,00/kWh dan gas secara teoritis Rp 1714,3 / kWh. Jika penjualan listrik Rp 1352,- / kWh, maka dengan menggunakan bahan bakar HSD akan berpotensi rugi sebesar Rp 1189,86/kWh secara akutal, Rp 984,00/kWh secara teoritis, dan Rp 362,00/kWh dengan menggunakan bahan bakar gas.
\end{abstract}

Kata Kunci : PLTG, HSD, LNG, Specific Fuel Consumption, SFC

\begin{abstract}
Gas Power Plant (PLTG) is one of the power plant used by PT. Indonesia Power UP Bali in the power plant industry in Indonesia. In operation from 1994 until now, the PLTG engine is still using diesel oil / HSD as fuel generator. This research is intended to analyze the performance of PLTG system, especially economic analysis by comparing the use of diesel fuel and gas in generating machine. Specific Fuel Consumption (SFC) is the ratio of total fuel consumption to electric power generated, SFC is used as one way to find out how efficient a generating machine and one determinant of production cost, especially fuel cost required in generating. Based on research results with the price of diesel oil / HSD Rp 7300, - / liter and gas US \$11 / mm BTU, the actual cost of producing HSD fuel electricity is $R p 2541,86 / \mathrm{kWh}$, theoretically $R p 2336,00 / \mathrm{kWh}$ and gas theoretically $R p 1714.3$ / $k W h$. If the sale of electricity is $R p 1352,-/ k W h$, then using HSD fuel will potentially lose as much as Rp $1189.86 / \mathrm{kWh}$ on a theoretical basis, Rp 984.00 / kWh theoretically, and Rp 362.00 / kWh using gas fuel.
\end{abstract}

Keywords: PLTG, HSD, LNG, Specific Fuel Consumption, SFC

Penulis korespondensi

Email: widigdha@yahoo.com 


\section{PENDAHULUAN}

PT. Indonesia Power Unit Pembangkitan Bali merupakan salah satu anak perusahaan dari PT. PLN (persero) yang menangani bisnis pembangkitan di Bali. Kegiatan operasi PLTG di PT. Indonesia Power Unit Pembangkitan Bali terdapat empat buah unit PLTG yang terdiri dari dua unit PLTG dengan Daya Mampu Netto (DMN) sebesar 18 MW dan dua unit PLTG dengan DMN sebesar 36 MW (Data Pembangkit UP Bali, September 2017). Pengoperasian empat buah unit PLTG mengakibatkan biaya produksi listrik di PT. Indonesia Power Unit Pembangkitan Bali masih relatif tinggi dibandingkan dengan harga jual yang ditawarkan kepada masyarakat. PT. Indonesia Power mengeluarkan biaya produksi Rp 1200 per Kilowatt Hour (KwH). Sedangkan harga jual hanya Rp 787 per KwH, sehingga biaya produksi kurang lebih sebesar Rp. 400 per $\mathrm{KwH}$ masih dibebankan kepada pemerintah sebagai subsidi (Adikumoro dkk, 2014). Analisis nilai Specific Fuel Consumption (SFC) pada mesin pembangkit listrik merupakan salah satu penentu biaya produksi khususnya biaya bahan bakar yang diperlukan dalam pembangkit. Dengan mengetahui konsumsi spesifik bahan bakar dapat menjelaskan seberapa optimal kinerja mesin untuk meningkatkan daya pembangkitan dan menimalisir pemborosan bahan bakar sehingga tercipta peluang penghematan biaya produksi.

Spesific Fuel Consumption (SFC) adalah rasio perbandingan total konsumsi bahan bakar terhadap daya listrik yang dibangkitkan dalam sebuah industri pembangkit listrik, biasanya digunakan sebagai salah satu cara untuk mengetahui seberapa efisien sebuah pembangkit listrik dan untuk memprediksi nilai kalor bahan bakar yang digunakan untuk pembakaran. Sebuah pembangkit bisa mengalami penyusutan kapasitas, misalnya pembangkit yang sebelumnya diketahui 100 Mega Watt, bisa turun setelah mesin dioperasikan 20-25 tahun. Berhubung karena umur dari pembangkit sudah mendekati kurang lebih 20 tahun maka perlu dilakukan kajian terhadap prestasi kerja pembangkit. Selain itu, analisis juga bisa dilaksanakan untuk mengetahui pemborosan yang mungkin terjadi akibat biaya perawatan dan biaya lain yang seharusnya tidak dikeluarkan. (Tempo Interaktif, Rabu 04 Juni 2003).

Penelitian ini mengkaji secara termodinamika daya pembangkit yang dihasilkan baik menggunakan bahan bakar gas, atau menggunakan bahan bakar minyak solar (HSD), terhadap prestasi kerja pembangkit yang meliputi efisiensi termal, konsumsi bahan bakar, dan analisis keekonomiannya.

\section{METODE}

Penelitian ini menganalisa perbandingan daya terbangkitkan dari sistem yang terpasang dengan daya terbangkitkan dari sistem yang terbangkitkan pada mesin PLTG akibat penggunaan bahan bakar minyak solar atau gas, menganalisa perbandingan konsumsi bahan bakar dari sistem yang terpasang dengan konsumsi bahan bakar dari sistem yang terbangkitkan pada mesin PLTG akibat penggunaan bahan bakar minyak solar atau gas dan menganalisa perbandingan keekonomian dari sistem yang terpasang dengan keekonomian dari sistem yang terbangkitkan pada mesin PLTG akibat penggunaan bahan bakar minyak solar atau gas. Metoda penelitian ini adalah mengkaji secara termodinamika daya pembangkit yang dihasilkan baik menggunakan bahan bakar gas, atau menggunakan bahan bakar minyak solar, terhadap prestasi kerja pembangkit yang meliputi daya terbangkitkan, konsumsi bahan bakar, dan analisis keekonomiannya.

Data primer yang langsung diambil dari hasil observasi lapangan, dalam hal ini nilai pengukuran temperatur kompresor, ruang bakar, dan turbin gas, serta spesifikasi pada mesin pembangkit. Kumpulan data teoritis yang diperoleh dari berbagai referensi pustaka, baik berupa buku, jurnal/artikel, tabel maupun data laporan tahunan dari instansi yang berhubungan dengan penelitian ini. Data yang diambil adalah temperature di masing - masing titik pengukuran, tekanan dan massa bahan bakar yang dikonsumsi. Pengolahan data dilakukan berdasarkan analisa data yang diperoleh untuk mengkaji secara termodinamika 
daya pembangkit yang dihasilkan baik menggunakan bahan bakar gas, atau menggunakan bahan bakar minyak solar.

\section{HASIL DAN PEMBAHASAN}

Data hasil penelitian pada mesin PLTG Unit 4 PT. Indonesia Power UP Bali bersumber dari logsheet harian mesin pembangkit pada tanggal 12 Agustus 2017 yang disajikan dalam Tabel 1.

Tabel 1. Tabel hasil pengamatan PLTG Unit 4

\begin{tabular}{|c|c|c|c|c|c|c|c|c|}
\hline \multirow{2}{*}{$\begin{array}{c}\text { Jam } \\
\text { WITA }\end{array}$} & \multicolumn{4}{|c|}{ Temperatur ( $\left.{ }^{\circ} \mathrm{C}\right)$} & \multicolumn{2}{|c|}{$\begin{array}{c}\text { Tekanan } \\
\text { (Psi) }\end{array}$} & \multirow{2}{*}{$\underset{(\mathbf{l p m})}{\dot{\mathbf{m}}_{\mathrm{BB}}}$} & \multirow{2}{*}{$\begin{array}{c}\text { Power } \\
\text { Output } \\
(\mathrm{MW})\end{array}$} \\
\hline & $\mathbf{T}_{1}$ & $\mathbf{T}_{2}$ & $\mathbf{T}_{3}$ & $\mathbf{T}_{4}$ & $\mathbf{P}_{1}=\mathbf{P}_{4}$ & $\mathbf{P}_{2}=\mathbf{P}_{3}$ & & \\
\hline 00.00 & 27.17 & 430.00 & 1104.25 & 521.00 & 14,69 & 212,00 & 223,53 & 38,47 \\
\hline 01.00 & 27.17 & 429.33 & 1104.30 & 521.17 & 14,69 & 211,83 & 223,53 & 38,47 \\
\hline 02.00 & 27.17 & 429.50 & 1104.34 & 521.83 & 14,69 & 212,00 & 223,53 & 38,47 \\
\hline 03.00 & 26.67 & 428.33 & 1104.71 & 521.67 & 14,69 & 211,67 & 223,53 & 38,47 \\
\hline 04.00 & 26.50 & 428.50 & 1104.99 & 521.67 & 14,69 & 211,50 & 223,53 & 38,47 \\
\hline 05.00 & 25.50 & 428.17 & 1105.45 & 521.17 & 14,69 & 211,17 & 223,53 & 38,47 \\
\hline 06.00 & 25.67 & 428.00 & 1105.45 & 521.87 & 14,69 & 210,67 & 223,53 & 38,47 \\
\hline 07.00 & 25.33 & 427.90 & 1105.00 & 522.00 & 14,69 & 210,17 & 223,53 & 38,47 \\
\hline 08.00 & 25.35 & 427.50 & 1105.63 & 522.83 & 14,69 & 209,83 & 223,53 & 38,47 \\
\hline 09.00 & 25.33 & 427.77 & 1105.79 & 522.83 & 14,69 & 209,33 & 223,53 & 38,47 \\
\hline 10.00 & 25.31 & 428.20 & 1106.00 & 522.83 & 14,69 & 208,83 & 223,53 & 38,47 \\
\hline 11.00 & 25.28 & 428.29 & 1106.07 & 523.00 & 14,69 & 208,33 & 223,53 & 38,47 \\
\hline 12.00 & 25.17 & 428.83 & 1106.10 & 523.50 & 14,69 & 207,83 & 223,53 & 38,47 \\
\hline 13.00 & 25.09 & 428.91 & 1106.34 & 523.50 & 14,69 & 207,80 & 223,53 & 38,47 \\
\hline 14.00 & 25.06 & 429.20 & 1106.40 & 523.70 & 14,69 & 207,70 & 223,53 & 38,47 \\
\hline 15.00 & 25.09 & 430.83 & 1106.40 & 523.50 & 14,69 & 208,50 & 223,53 & 38,47 \\
\hline 16.00 & 25.33 & 431.50 & 1106.00 & 523.33 & 14,69 & 209,33 & 223,53 & 38,47 \\
\hline 17.00 & 26.11 & 432.17 & 1105.76 & 522.50 & 14,69 & 210,83 & 223,53 & 38,47 \\
\hline 18.00 & 26.75 & 432.83 & 1105.45 & 522.33 & 14,69 & 210,83 & 223,53 & 38,47 \\
\hline 19.00 & 27.81 & 431.50 & 1105.30 & 522.33 & 14,69 & 210,50 & 223,53 & 38,47 \\
\hline 20.00 & 27.72 & 430.67 & 1105.30 & 521.67 & 14,69 & 212,67 & 223,53 & 38,47 \\
\hline 21.00 & 27.67 & 429.50 & 1104.66 & 520.83 & 14,69 & 211,17 & 223,53 & 38,47 \\
\hline 22.00 & 27.17 & 429.33 & 1104.40 & 520.83 & 14,69 & 211,67 & 223,53 & 38,47 \\
\hline 23.00 & 27.17 & 429.33 & 1104.30 & 520.83 & 14,69 & 212,67 & 223,53 & 38,47 \\
\hline
\end{tabular}

Sumber : Control Room PLTG Pesanggaran

Keterangan data dalam Tabel 1 diketahui sebagai berikut :

$\begin{array}{lll}- & \mathrm{T}_{1} & \text { = temperature udara luar }\left({ }^{\circ} \mathrm{C}\right) \\ \text { - } & \mathrm{T}_{2} & =\text { temperature udara setelah melalui kompresor }\left({ }^{\circ} \mathrm{C}\right) \\ \text { - } & \mathrm{T}_{3} & =\text { temperature udara setelah melalui ruang bakar }\left({ }^{\circ} \mathrm{C}\right) \\ \text { - } & \mathrm{T}_{4} & \text { = temperature udara setelah melalui turbin }\left({ }^{\circ} \mathrm{C}\right) \\ \text { - } & \mathrm{P}_{1}=\mathrm{P}_{4} & =\text { tekanan udara luar }(\mathrm{psia}) \\ \text { - } & \mathrm{P}_{2}=\mathrm{P}_{3} & =\text { tekanan setelah melalui kompresor (psia) } \\ \text { - } & \dot{\mathrm{m}}_{\mathrm{BB}} & =\text { laju alir massa bahan bakar }(1 \mathrm{pm}) \\ \text { - } & \text { Power Output } & =\text { daya terbangkitkan }(\mathrm{MW})\end{array}$

Tabel 2. Tabel perhitungan entalphi dan kerja sistem di tiap titik pengukuran dari jam $00.00-23.00$

Wita

\begin{tabular}{|c|c|c|c|c|c|c|c|c|c|}
\hline \multirow{2}{*}{$\begin{array}{c}\text { Waktu } \\
\text { (WITA) }\end{array}$} & \multicolumn{4}{|c|}{$\begin{array}{c}\text { Entalphi (h) } \\
(\mathrm{kJ} / \mathrm{kg})\end{array}$} & \multicolumn{3}{|c|}{$\begin{array}{c}\text { Kerja }(W) \\
(\mathbf{k J} / \mathbf{k g})\end{array}$} & \multirow{2}{*}{$\underset{(k J / k g)}{q_{\text {in }}}$} & \multirow{2}{*}{$\begin{array}{c}\eta_{\text {th }} \\
(\%)\end{array}$} \\
\hline & $\mathbf{h}_{1}$ & $\mathbf{h}_{2}$ & $\mathbf{h}_{3}$ & $\mathbf{h}_{4}$ & $\mathbf{W}_{\mathrm{K}}$ & $\mathbf{W}_{\mathrm{T}}$ & $\mathbf{W}_{\text {nett }}$ & & \\
\hline $00: 00$ & 300,36 & 716,50 & 1488,15 & 815,37 & 356,26 & 604,63 & 248,37 & 771,65 & 32,19 \\
\hline 01:00 & 300.36 & 715.78 & 1488.21 & 815.56 & 355.64 & 604,51 & 248,87 & 772,43 & 32,22 \\
\hline $02: 00$ & 300.36 & 715.96 & 1488.25 & 816.28 & 355.80 & 603,90 & 248,10 & 772,29 & 32,13 \\
\hline 03:00 & 299.86 & 714.70 & 1488.70 & 816.11 & 355.15 & 604,46 & 249,31 & 774,00 & 32,21 \\
\hline 04:00 & 299.69 & 714.89 & 1489.03 & 816.11 & 355.45 & 604,76 & 249,31 & 774,15 & 32,20 \\
\hline 05:00 & 298.68 & 714.53 & 1489.58 & 815.56 & 356.01 & 605,74 & 249,74 & 775,05 & 32,22 \\
\hline 06:00 & 298.85 & 714.35 & 1489.58 & 816.33 & 355.70 & 605,06 & 249,35 & 775,24 & 32,16 \\
\hline $07: 00$ & 298.51 & 714.24 & 1489.05 & 816.47 & 355.90 & 604,44 & 248,54 & 774,81 & 32,08 \\
\hline 08:00 & 298.53 & 713.81 & 1489.80 & 817.38 & 355.52 & 604,30 & 248,79 & 775,99 & 32,06 \\
\hline 09:00 & 298.51 & 714.10 & 1489.99 & 817.38 & 355.78 & 604,48 & 248,69 & 775,89 & 32,05 \\
\hline $10: 00$ & 298.49 & 714.56 & 1490.24 & 817.38 & 356.20 & 604,70 & 248,50 & 775,68 & 32,04 \\
\hline $11: 00$ & 298.46 & 714.66 & 1490.33 & 817.57 & 356.31 & 604,61 & 248,30 & 775,67 & 32,01 \\
\hline $12: 00$ & 298.35 & 715.24 & 1490.36 & 818.11 & 356.90 & 604,15 & 247,25 & 775,12 & 31,90 \\
\hline
\end{tabular}




\begin{tabular}{|c|c|c|c|c|c|c|c|c|c|}
\hline 13:00 & 298.27 & 715.33 & 1490.65 & 818.11 & 357.04 & 604,41 & 247,37 & 775,32 & 31,90 \\
\hline $14: 00$ & 298.24 & 715.64 & 1490.72 & 818.33 & 357.34 & 604,28 & 246,94 & 775,08 & 31,86 \\
\hline $15: 00$ & 298.27 & 717.39 & 1490.72 & 818.11 & 358.81 & 604,47 & 245,66 & 773,33 & 31,77 \\
\hline $16: 00$ & 298.51 & 718.12 & 1490.24 & 817.93 & 359.22 & 604,21 & 244,99 & 772,13 & 31,73 \\
\hline $17: 00$ & 299.30 & 718.84 & 1489.96 & 817.02 & 359.17 & 604,77 & 245,60 & 771,12 & 31,85 \\
\hline 18:00 & 299.94 & 719.55 & 1489.58 & 816.83 & 359.23 & 604,60 & 245,37 & 770,03 & 31,87 \\
\hline 19:00 & 301.00 & 718.12 & 1489.40 & 816.83 & 357.09 & 604,44 & 247,35 & 771,29 & 32,07 \\
\hline $20: 00$ & 300.91 & 717.22 & 1489.40 & 816.11 & 356.40 & 605,09 & 248,69 & 772,18 & 32,21 \\
\hline $21: 00$ & 300.86 & 715.96 & 1488.64 & 815.19 & 355.37 & 605,23 & 249,86 & 772,68 & 32,34 \\
\hline $22: 00$ & 300.36 & 715.78 & 1488.33 & 815.19 & 355.64 & 604,95 & 249,31 & 772,55 & 32,27 \\
\hline $23: 00$ & 300.36 & 715.78 & 1488.21 & 815.19 & 355.64 & 604,84 & 249,20 & 772,43 & 32,26 \\
\hline Rata-rata & 299.38 & \begin{tabular}{|l|}
715.88 \\
\end{tabular} & 1489.46 & 816.69 & 356.57 & 604,63 & 248,06 & 773,59 & 32,07 \\
\hline
\end{tabular}

\section{Analisa Keteknikan}

Tabel 3. Perbandingan nilai daya hasil perhitungan

\begin{tabular}{|c|c|c|c|}
\hline Uraian & Bahan Bakar HSD (aktual) & $\begin{array}{c}\text { Bahan Bakar HSD } \\
\text { (teoritis) }\end{array}$ & $\begin{array}{c}\text { Bahan Bakar LNG } \\
\text { (teoritis) }\end{array}$ \\
\hline LHV $(\mathrm{kJ} / \mathrm{kg})$ & 45564,34 & 45564,34 & 49152,60 \\
\hline $\mathrm{h}_{1}(\mathrm{~kJ} / \mathrm{kg})$ & 299,38 & 299,38 & 299,38 \\
\hline $\mathrm{h}_{2}(\mathrm{~kJ} / \mathrm{kg})$ & 715,88 & 715,88 & 715,88 \\
\hline $\mathrm{h}_{3}(\mathrm{~kJ} / \mathrm{kg})$ & 1489,46 & 1489,46 & 1489,46 \\
\hline $\mathrm{h}_{4}(\mathrm{~kJ} / \mathrm{kg})$ & 816,69 & 816,69 & 816,69 \\
\hline $\mathrm{W}_{\mathrm{k}}(\mathrm{kJ} / \mathrm{kg})$ & 356,57 & 356,57 & 356,57 \\
\hline $\mathrm{W}_{\mathrm{T}}(\mathrm{kJ} / \mathrm{kg})$ & 604,63 & 604,63 & 604,63 \\
\hline $\mathrm{q}_{\text {in }}(\mathrm{kJ} / \mathrm{kg})$ & 773,59 & 773,59 & 773,59 \\
\hline $\mathrm{W}_{\text {nett }}(\mathrm{kJ} / \mathrm{kg})$ & 248,06 & 248,06 & 248,06 \\
\hline$\eta_{\text {th }}(\%)$ & 32,07 & 32,07 & 32,07 \\
\hline$\dot{\mathrm{m}}_{\mathrm{bb}}(\mathrm{kg} / \mathrm{s})$ & 3,13 & 3,13 & 2,9 \\
\hline$\dot{\mathrm{m}}_{\mathrm{ud}}(\mathrm{kg} / \mathrm{s})$ & 165,2 & 165,2 & 165,2 \\
\hline Daya Perencanaan $(\mathrm{kW})$ & 42070 & - & - \\
\hline Daya $(\mathrm{N})$ rata-rata $(\mathrm{kW})$ & 38470 & 41756 & 41699,04 \\
\hline Penyusutan Daya Pembangkit & 3600 & 313,92 & - \\
\hline Selisih Aktual - Teoritis (kW) & 0 & 3286,08 & - \\
\hline Pemborosan (\%) & 0 & 7,87 & - \\
\hline Produksi Listrik Perhari (kWh) & $923.280,00$ & $1.002 .144,00$ & $1.000 .776,96$ \\
\hline $\mathrm{SFC}(\mathrm{kg} / \mathrm{kWh})$ & 0,29 & 0,27 & 0,25 \\
\hline SFC (lt/kWh) & 0,3482 & 0,32 & 0,297 \\
\hline
\end{tabular}

Dari Tabel 3 di atas dapat dijelaskan melalui analisi sebagai berikut,

a. Entalpi Sistem (h) dari titik pengukuran 1 sampai 4 adalah nilai-nilai yang didasarkan pada penentuan asumsi fluida kerja yaitu gas ideal.

b. Kerja Kompresor $\left(\mathrm{W}_{\mathrm{K}}\right)$ adalah kerja yang dilakukan kompresor. dihitung dengan selisih antara entalpi fluida kerja sebelum dan sesudah keluar dari kompresor. Secara teoritis kerja kompresor dapat diturunkan dengan menaikkan $\mathrm{h}_{1}$, yaitu dengan cara melakukan pemanasan awal udara yang akan masuk ke dalam kompresor, atau menurunkan $\mathrm{h}_{2}$, dengan cara mendinginkan casing kompresor.

c. Kerja Turbin $\left(\mathrm{W}_{\mathrm{T}}\right)$ dapat dihitung dengan selisih antara entalpi fluida kerja sebelum dan sesudah melalui turbin. Kerja turbin digunakan untuk menggerakkan kompresor dan perangkat lainnya. Sisa kerja turbin kemudian digunakan untuk menggerakkan generator.

d. Panas Masuk Sistem $\left(\mathrm{q}_{\text {in }}\right)$ dapat dihitung dengan selisih antara entalpi fluida kerja sebelum dan sesudah melalui ruang bakar. Panas masuk sistem merupakan fungsi dari temperatur masuk ruang bakar, nilai kalor bahan bakar dan efisiensi ruang bakar.

e. Efisiensi thermal merupakan perbandingan antara kerja netto yang dibutuhkan sistem pembangkit dengan kalor yang masuk pada sistem, atau kerja yang bisa dihasilkan sistem. Secara aktual, dan teoritis pada saat penggunaan HSD dan LNG adalah sama. Hal ini bisa terjadi karena penekanan penggantian bahan bakar bukan pada efisiensi thermisnya, tetapi efisiensi dari tinjauan keekonomian. 
f. Penyusutan Daya Pembangkit terjadi salah satunya karena umur pakai, bahwa pembangkit listrik akan mengalami penurunan kemampuan daya setelah dioperasikan beberapa puluh tahun. Dalam kasus di PLTG Pesanggaran, khususnya Unit 4, penurunan daya yang terjadi adalah sebesar 3,6 MW. Jika dioperasikan terus, maka semakin tahun akan semakin bertambah tingkat penyusutannya.

g. Daya Pembangit diketahui dari alat ukur yang terpasang pada sistem. Daya ini adalah daya riil yang dihasilkan sistem. Daya ini bisa dikoreksi dengan menghitung daya yang seharusnya dihasilkan sistem dengan pendekatan properties fluida kerja pada titik-titik pengukuran yang telah ditetapkan. Daya yang dihasilkan dengan penggunaan bahan bakar HSD secara aktual adalah $38470 \mathrm{~kW}$, daya teoritis yang seharusnya dihasilkan adalah $41756 \mathrm{~kW}$. Dari cara kedua untuk mengetahui daya pembangkit yang seharusnya dihasilkan bisa digunakan sebagai dasar penetapan tingkat pemborosan, atau peluang penghematan yang bisa dilakukan. Akibat dari penggantian bahan bakar dengan LNG, terjadi penurunan daya pembangkit yaitu $56,96 \mathrm{~kW}$ menjadi $41699,04 \mathrm{~kW}$. Hal ini terjadi karena adanya penurunan laju aliran massa bahan bakar dari $3,13 \mathrm{~kg} / \mathrm{s}$ HSD menjadi 2,9 $\mathrm{kg} / \mathrm{s}$ LNG. Penurunan laju aliran massa ini perlu dilakukan untuk menjaga temperatur tertinggi $\left(\mathrm{T}_{3}\right)$ tetap. Hal ini perlu dilakukan karena material mempunyai keterbatasan ketahanan terhadap temperatur tinggi pada waktu yang lama.

h. Produksi listrik merupakan hasil kali antara daya terbangkitkan dengan waktu operasi. PLTG G4 Pesanggaran, dijalankan 24 jam sehari, artinya produksi listrik aktual adalah 923.280,00 kWh atau 923,2 MWh, secara teoritis dengan bahan bakar HSD berdasarkan properties fluida kerjanya adalah $1.002 .144,00 \mathrm{kWh}$ atau 1002,1 MWh. Dalam satu hari, peluang penghematan pembangkit adalah $78864 \mathrm{kWh}$. Perhitungan secara ekonomi akan disampaikan dalam analisis ekonomi Sedangkan perhitungan dengan pemakaian LNG sebagai fluida kerja adalah sebesar 1.000.776,96 kWh atau, 1000,8 MWh. Jika dibandingkan dengan perhitungan secara teoritis terjadi penurunan produksi listrik, yaitu $1367,04 \mathrm{kWh}$. Hal ini terjadi karena adanya penurunan daya akibat penurunan laju aliran massa LNG pembakaran.

i. Specific Fuel Consumption (SFC) merupakan perbandingan antara bahan bakar yang digunakan sistem dengan daya yang dihasilkan sistem dengan penggunaan bahan bakar tersebut. SFC pada umumnya dinyatakan dalam satuan yang bisa menggambarkan nilai ekonomisnya. Misalnya, dalam penggunaan BBM pernyataan SFC pada umumnya dinyatakan dalam liter/kWh, hal ini dipilih mengingat BBM dalam penjualannya dalam satuan volume bukan satuan massa, mengingat properties BBM tidak mengalami perubahan yang mencolok akibat perubahan temperatur lingkungan. Hal ini berbeda dengan bahan bakar gas (BBG). Volume BBG merupakan fungsi dari temperatur dan tekanan. Oleh karena itu lebih umum digunakan $\mathrm{kg} / \mathrm{kWh}$ dari pada liter/kWh. Dari pengamatan dan Perhitungan yang dilakukan SFC aktual adalah 0,3482 liter/kWh dan secara teoritis adalah 0,32 liter/kWh. Ada penurunan SFC dari kondisi teoritis ke kondisi aktual. Hal ini terjadi karena adanya penurunan daya akibat adanya pemborosan yang terjadi. Dalam pemakaian LNG, besarnya SFC adalah $0,25 \mathrm{~kg} / \mathrm{kWh}$ atau 0,297 liter/kWh. 


\section{Analisa Keekonomian}

Tabel 4. Tabel Analisa Keekonomian

\begin{tabular}{|c|c|c|c|}
\hline Uraian & $\begin{array}{c}\text { Bahan Bakar HSD } \\
\text { (aktual) }\end{array}$ & $\begin{array}{c}\text { Bahan Bakar HSD } \\
\text { (teoritis) }\end{array}$ & Bahan Bakar LNG (teoritis) \\
\hline Biaya Produksi Listrik (Rp/kWh) & 2541,86 & 2336 & 1714,3 \\
\hline Potensi Penghematan $(\mathrm{Rp} / \mathrm{kWh})$ & 0 & 205,86 & 621,7 \\
\hline $\begin{array}{llll}\text { Harga Jual Listrik } & \text { PLN } & \text { (Rp } \\
1352 / \mathrm{kWh})\end{array}$ & $\begin{array}{r}1189,86 \\
\text { (rugi) }\end{array}$ & $\begin{array}{r}\text { (-) } 984 \\
\text { (rugi) }\end{array}$ & $\begin{array}{r}(-) 362 \\
\text { (rugi) }\end{array}$ \\
\hline $\begin{array}{l}\text { Potensi Kerugian/Keuntungan } \\
\text { Perhari (Rp/hari) }\end{array}$ & $\begin{array}{r}-(-098.573 .941,00 \\
\text { (defisit) }\end{array}$ & $\begin{array}{r}-) 986.109 .696,00 \\
\text { (defisit) }\end{array}$ & $\begin{array}{r}\text { (-) } 362.281 .259,50 \\
\text { (defisit) }\end{array}$ \\
\hline
\end{tabular}

Dari Tabel 4. di atas dapat dilakukan beberapa analisa. Biaya produksi listrik per kWh merupakan hasil kali dari SFC dengan harga bahan bakar. Dari harga HSD Rp 7300,00 maka biaya produksi listrik ke kWh adalah Rp 2541,86 pada kondisi aktualnya, dan seharusnya bisa ditekan biaya pembangkitan menjadi Rp $2336 / \mathrm{kWh}$, atau ada penghematan Rp 205,86/kWh. Nilai ini menjadi nilai yang sangat besar apabila dikalikan dengan angka pembangkitan yang tinggi. Sebagai contoh, besar potensi yang bisa dihemat dalam satu hari adalah Rp. 205,86 /kWh x 923.280,00 kWh = Rp 191.919.160,80 per hari.

Biaya produksi listrik dengan penggantian bahan bakar LNG menjadi jauh lebih murah jika dibandingkan dengan penggunaan HSD, yaitu $\mathrm{Rp} 1714,3 / \mathrm{kWh}$. Besar penghematan adalah sebesar Rp $621,70 / \mathrm{kWh}$. Apabila PLN menjual listrik kepada pelanggannya rata-rata $\mathrm{Rp} 1352$,- $/ \mathrm{kWh}$ maka dengan pamakain LNG (harga LNG 11 $\mathrm{USD} / \mathrm{mmBtu}$ ) dapat menekan biaya menjadi Rp. 362,00/kWh.

Akibat adanya pemborosan pembangkitan sebesar 7,87\% maka dalam perhitungan ekonomi juga mengalami kerugian. Sedangkan besar penekanan keuangan perusahaan yang bisa dilakukan dengan penggunaan LNG adalah sebesar Rp 362.281.259,50 per hari.

\section{SIMPULAN}

Berdasarkan data dan analisa data, disimpulkan bahwa daya terbangkitkan pada sistem PLTG Unit 4 yang menggunakan bahan bakar solar mengalami penurunan, di mana daya terbangkitkan dari spesifikasi teknis adalah sebesar 42 MW, sedangkan daya aktual yang terbangkitkan adalah sebesar 38,47 MW. Secara teoritis daya terbangkitkan juga dapat dihitung dan didapatkan hasil sebesar 41,76 MW, sedangkan daya terbangkitkan menggunakan bahan bakar LNG secara teoritis sebesar 41,70 MW. SFC mesin pembangkit menggunakan HSD secara aktual adalah $0,35 \mathrm{lt} / \mathrm{kWh}$, dan secara teoritis adalah $0,32 \mathrm{lt} / \mathrm{kWh}$, sedangkan SFC mesin pembangkit menggunakan LNG adalah 0,297 lt/kWh atau sama dengan $0,25 \mathrm{~kg} / \mathrm{kWh}$. Ada penurunan SFC dari kondisi teoritis ke kondisi aktual. Biaya produksi listrik yang dihasilkan mesin pembangkit menggunakan bahan bakar HSD non subsidi dengan harga Rp 7300,- secara aktual didapatkan sebesar Rp 2.541,00 /kWh, sedangkan secara teoritis sebesar Rp 2.336,00 /kWh. Biaya produksi listrik dengan menggunakan bahan bakar LNG sebesar Rp 1714,30/kWh.

\section{DAFTAR PUSTAKA}

[1] Sunarwo, dan M, Teguh Harijono., (2016), Analisa Efisiensi Turbin Gas Unit 1 Sebelum Dan Setelah Overhaul Combustor Inspection Di Pt Pln (Persero) Sektor Pembangkitan Pltgu Cilegon, Jurnal Teknik Energi Vol 12 No. 2 Mei 2016; 50-57.

[2] Kurniawan, Rahmat., MulfiHazwi, (2014), Analisa Performansi Pembangkit Listrik Tenaga Gas Uap (Pltgu) Sicanang Belawan, Jurnal e-Dinamis, Volume.10, No.2 September 2014 ISSN 2338-1035.

[3] Habiba, H.Muh Syahrir., F.Cahyadi, Suryani, (2006), Analisis Efektifitas Sistem Pembangkit Listrik Tenaga Gas Dan Uap (Pltgu) Pada Pt. Energi Sengkang, ILTEK, 
Volume I, Nomor 2, April 2006.

[4] Naryono., Lukman Budiono, Analisis Efisiensi Turbin Gas Terhadap Beban Operasi Pltgu Muara Tawar Blok 1, SINTEK VOL 7 NO 2 Page 78.

[5] Sitepu, Tekad., (2010), Kajian Penggunaan Kompresor Aksial, Jurnal Dinamis Vol. II, No. 6, Januari 2010 ISSN $0216-7492$.

[6] Adikumoro, Bogi., Dwi Novirani, Lisye Fitria, (2014), Pengaruh Pembebanan Pembangkit Listrik Tenaga Gas Terhadap Efisiensi Biaya Pembangkitan Listrik (Studi Kasus di PT. Indonesia Power UBP Bali Unit Pesanggaran). Reka Integra ISSN: 23385081 CJurusan Teknik Industri Itenas | No. 02|Vol. 02 Jurnal Online Institut Teknologi Nasional April 2014.

[7] Cengel, Yunus A;2002: Fifth Edition Thermodynamics An Engineering Approach. McGraw-Hill. New York, United State of America. 